\title{
Coalescence efficiency model including electrostatic interactions in liquid/liquid dispersions
}

\author{
Johannes Kamp ${ }^{1 *}$, Matthias Kraume ${ }^{1}$ \\ ${ }^{1}$ Chair of Chemical \& Process Engineering, Technische Universität Berlin, \\ Straße des 17. Juni 135, FH 6-1, 10623 Berlin, Germany \\ *Corresponding author: Johannes.Kamp@tu-berlin.de Tel.: +493031423171
}

\begin{abstract}
The drop size distribution is an essential process variable in liquid/liquid systems and relevant in many technical applications. It can be described by population balance equations. A coalescence efficiency model was developed to be able to describe the well-known coalescence inhibition due to changing $\mathrm{pH}$ value or salt concentration. The model includes the attractive van der Waals and repulsive electrostatic force according to the DLVO theory into the population balance equation framework. This DLVO model can extend existing simulations in a straightforward manner due to a conceptual implementation. Moreover, zeta potential measurements were performed and the model was applied to simulate experiments in a stirred tank. Hence, the drop size distribution could be predicted well with changing $\mathrm{pH}$ value. The results are discussed in comparison to simulations with existing models in literature.
\end{abstract}

\section{Keywords}

population balance; coalescence; DLVO; electrostatic force; zeta potential; coalescence efficiency

\section{Introduction}

Liquid/liquid systems are an integral part of many unit operations in which the liquid phases are either dispersed or separated. The drop size distribution which is the result of the competing phenomena of drop breakage and coalescence determines a decisive part of the overall process efficiency. Although these processes were investigated quite frequently, they are by no means completely understood.

The population balance equation (PBE) is a modelling approach which accounts for the droplet interactions and describes the time dependent drop size distribution by death and birth terms for drop breakage and coalescence (Hulburt and Katz, 1964; Kopriwa et al., 2012; Ramkrishna, 2000, 1985; Randolph and Larson, 1962). These terms consist of mechanistic sub models based on single drop interactions depending on the drop size and system conditions (e.g. energy dissipation, viscosities and interfacial tension). The modular concept of the population balance equation allows a simple implementation and exchange of sub models which are available in literature for (I) drop breakage (consisting of breakage rate and daughter drop size distribution) (Liao and Lucas, 2009) and for (II) drop coalescence (consisting of collision frequency and coalescence efficiency) (Liao and Lucas, 2010). The collision frequency determines the rate how often droplets in a system collide with each other whereas the coalescence efficiency describes the probability that two interacting drops merge into one. Together they form the coalescence rate. Up to now, a reliable prediction of the coalescence rate and thus the drop size distribution accounting for all influencing chemical, geometrical and process parameters is not available. Accordingly, further investigations and developments are necessary (Liao and Lucas, 2009). Existing models include influencing factors of the chemical composition like density, viscosity and interfacial tension. But also other properties such as the electrostatic interactions, which are not implemented properly so far, influence the coalescence significantly. 
The coalescence of drops can be hindered by steric obstruction but also massively by electrochemical effects (Rambhau et al., 1977; Watanabe, 1984) up to a formation of a stable emulsion. A charge separation induces an electrostatic potential at the interface of the droplets which again is dampened by the solute ions in the continuous phase (Lyklema, 2000). Altogether, an electrostatic repulsive force results between two approaching droplets. However, this effect is not as easy to be implemented in liquid/liquid systems as in the case of solid particles in an electrolyte solution. In the latter case, the charged particle surface is surrounded by the electrical double layer: one fixed layer of ions with opposing charge bound to the particle surface and a diffusive layer of ions dampening the excess charge of the covered surface (Delgado et al., 2007; Israelachvili, 1991). Although the reality is often more complex than this simple picture, the situation at a liquid/liquid interface is even more complicated. A fixed layer of ions at a mobile interface seems to be quite unlikely. Consequently, mobile ions at the surface will lead to a locally inhomogeneous charge due to movement of the surface (Carroll, 1976). Additionally, it is known that the solubility of ions in oil is small though non-zero (Izutsu, 2002; Wagner et al., 1998), inevitably a partition of the ions between the two phases occurs and two electric 'double' layers are formed at both sides of the interphase (Derjaguin et al., 1987). Although the induced potentials were measured by several authors, the origin of the electrostatic potential at the interface is discussed in a controversial manner in literature. Some authors argue solely by means of dissimilar partition coefficients of the present ions in the oil and water phase (Overbeek, 1952; Pfennig and Schwerin, 1998). Assuming different partition coefficients of the ions and applying the Albertsson model (Pfennig and Schwerin, 1998), it was shown that only the relative magnitude of the partition coefficients may determine the potential difference at the surface. Another widely used assumption is the preferred accumulation or adsorption of specific ions at the interface (especially hydroxide ions (Beattie and Djerdjev, 2004; Beattie and Gray-Weale, 2012; Beattie et al., 2005; Creux et al., 2009; Franks et al., 2005; Gray-Weale and Beattie, 2009; Marinova et al., 1996)), whether it is described by Gibbs (Lyklema, 2000) or Langmuir monolayers (Marinova et al., 1996; Tian and Shen, 2009). Other research groups doubt this concept of ion adsorption and attribute the created potential to the immobilization and orientation of water dipoles at the surface (Chibowski et al., 2005; Vacha et al., 2011) or to the deprotonation of fatty acid impurities in the oil (Roger and Cabane, 2012a, 2012b).

The van der Waals force is the opposing attractive force acting on particles in the same range of magnitude and distance (few tens of nanometres). The counter play of the repulsing electrostatic and the attractive van der Waal force is well known as DLVO theory (Derjaguin and Landau, 1941; Verwey and Overbeek, 1948). However, this theory has not been considered in population balance equations up to now. The only model regarding electrostatic forces was published by Tobin and Ramkrishna (1999), in which the authors introduce an additional varying parameter for the description of the repulse forces. An application and discussion of this model can be found in Kamp et al. (2012) and a short summary in section 3.2.1.

Although there is no technically relevant model available describing the above mentioned ion phenomena, there are several reports describing the influence of salts on liquid/liquid dispersions. The investigations of Tobin and Ramkrishna (1992) in stirred liquid/liquid systems showed that an increase in $\mathrm{pH}$ results in a decrease of drop sizes which was attributed to the coalescence inhibition caused by adsorption of hydroxide ions at the interface and a resulting repulsive force. With addition of sodium chloride and therefore rising ionic strength, the coalescence inhibition was reduced and the drop sizes in the system increased, which agrees with the DLVO theory. The decrease of the drop size distribution at high $\mathrm{pH}$ values in a stirred tank is also described by Gäbler et al. (2006) and Kraume et al. (2004). The authors explain this effect by an increasing coalescence inhibition with higher pH values. Kraume et al. (2004) also showed the dependency of the coalescence inhibi- 
tion from the $\mathrm{NaCl}$ concentration in shaken flask experiments. The settling time, meaning the time after which a dispersed system is settled into two separate phases, increases with higher pH value and decreases with higher salt concentration. Pfennig and Schwerin (1998) also found a strong coalescence inhibition in batch settling experiments adding $\mathrm{NaCl}$ and $\mathrm{NaBr}$ to a water in 1-butanol emulsion. According to the DLVO theory, they found the depletion of the coalescence inhibition with further increased salt concentration due to the dampening behaviour of the ions in the diffusive electrical layer.

The influence of salts on droplet coalescence was investigated by Villwock et al. (2014) observing the collision of two single droplets. A decrease of coalescence probability was found with the addition of both $\mathrm{NaOH}$ and $\mathrm{NaCl}$. Accordingly, Dunstan (1992) observed chloride adsorption on hydrocarbon particles and found an increasing zeta potential with higher $\mathrm{KCl}$ concentration. He explained this by a preferential solubility of $\mathrm{Cl}^{-}$ions near the surface and not by adsorption. Marinova et. al (1996) found $\mathrm{OH}^{-}$being the potential determining ion in xylene/water emulsions by performing zeta potential measurements with varying $\mathrm{pH}$ at an ionic strength of $I=10^{-3} \mathrm{~mol} / \mathrm{L}$. Tian and Shen (2009) investigated the adsorption of $\mathrm{H}_{3} \mathrm{O}^{+}, \mathrm{OH}^{-}$and $\mathrm{Cl}^{-}$at the octadecyltrichlorosilane/water interface and found the adsorption of $\mathrm{OH}^{-}$to be preferential against $\mathrm{Cl}^{-}$and $\mathrm{H}_{3} \mathrm{O}^{+}$. Considering these mentioned publications it becomes obvious that $\mathrm{Cl}^{-}$has to be considered besides $\mathrm{OH}^{-}$if studying the surface potential in a system containing those ions.

Another interesting fact is the small influence of the oil phase in this context. Marinova et. al (1996) investigated emulsions of different non-polar oils (xylene, dodecane, hexadecane and perfluoromethyldecalin) and found practically the same zeta potential under identical experimental conditions for all systems. This result was confirmed by the investigations of Creux et al. (2009) who found similar $\mathrm{pH}$ dependencies of the zeta potential of nitrobenzene, benzene, octane, decane and dodecane. Thus, the electrostatic effects appear to be nearly independent from the type of oil, and zeta potential measurements of one specific oil can be adopted universally.

\section{Materials \& methods}

All experiments were carried out using water as continuous and toluene as disperse phase. To set the $\mathrm{pH}$ value and the ionic strength sodium hydroxide, hydrochloric acid and sodium chloride were used. All equipment used was made of glass, stainless steel or PTFE where possible. Serious effort was made in all set-ups to avoid contaminations. Hence all equipment was cleaned thoroughly and rinsed with deionised water extensively prior to use.

\subsection{Experimental investigations in stirred tank}

The experiments were performed by Wegener (2004) previously at our institute and were published partly in the PhD thesis of Gäbler (2007) and in Kamp et al. (2012). To detect the drop size distribution (at $\mathrm{T}=293 \mathrm{~K}$ ) in a baffled stirred tank DN150 $(H / D=1)$ equipped with a Rushton turbine $(d / D=0.33)$ an endoscope technique was used. For detailed description of this set-up and measurement technique see Maaß et al. (2011) and Ritter and Kraume (2000). Continuous phase was deionised water with added $\mathrm{NaOH}$ (Merck 1.09956 p.a.), NaCl (Merck 1.06404 p.a.) and $\mathrm{HCl}$ (Merck 1.09970 p.a.) to set $\mathrm{pH}$ and a constant ionic strength $(I=0.1 \mathrm{~mol} / \mathrm{L})$. As disperse phase toluene was used with a volumetric phase fraction of $\varphi=0.1$. The drop size distributions were measured for the $\mathrm{pH}$ values $1,3,5,7,9,11$ and 13 each with three stirrer frequencies $(n=400,550$, $700 \mathrm{~min}^{-1}$ ) at distinct times after the start of the impeller. The experimental stirrer frequencies correspond to mean energy dissipation rates in the stirred tank of $\epsilon=0.133,0.345$ and $0.712 \mathrm{~m}^{2} / \mathrm{s}^{3}$. 


\subsection{Experimental determination of electrophoretic mobility}

The sample preparation was done in a similar manner to the procedure applied by Marinova et al. (1996). The $\mathrm{pH}$ of the water continuous phase (ultrapure water with a resistivity of $18.3 \mathrm{M} \Omega \cdot \mathrm{cm}$, produced by the purification system Merck Millipore Milli-Q Gradient) was adjusted with hydrochloric acid (Merck 1.09970 p.a.) and accordingly sodium hydroxide (Merck 1.09956 p.a.). To set a constant ionic strength of $I=0.1 \mathrm{~mol} / \mathrm{L}$, sodium chloride (Merck 1.06404 p.a.) was added respectively. Due to the sensitive unbuffered aqueous solution, the $\mathrm{pH}$ was measured by a pH-meter (WTW pH197) and indicator strips (VWR ProLabo Dosatest 3 zones). Due to the minor effect of dissolved carbon dioxide $\left(\mathrm{CO}_{2} / \mathrm{HCO}_{3}{ }^{-} / \mathrm{CO}_{3}{ }^{2-}\right)$ reported by Marinova et al. (1996), a purging of $\mathrm{CO}_{2}$ with $\mathrm{N}_{2}$ was omitted. Nevertheless, all serial dilutions and samples were closed as fast as possible to minimize the contact with the atmosphere and an additional dissolution of $\mathrm{CO}_{2}$. The samples were each prepared with $10 \mathrm{~mL}$ water continuous phase and 3 - $5 \mathrm{~mL}$ toluene (Fluka 89681-2.5L p.a.) in $20 \mathrm{~mL}$ vials with a magnetic stirrer. These vials were stirred and heated to $65^{\circ} \mathrm{C}$ in a water bath for at least 2 hours to increase the solubility of toluene in the water phase (Jou and Mather, 2003; Tsonopoulos, 2001). Prior to a measurement, the respective sample was cooled down rapidly to $25^{\circ} \mathrm{C}$ by rinsing with tap water from the outside, which causes a precipitation of the excess toluene in the water phase. The generated emulsion with a drop size distribution between $d_{p} \approx 2-7 \mu \mathrm{m}$ and a mean diameter of $d_{m}=5 \mu \mathrm{m}$ (measured with Malvern Zetasizer Nano ZS) remained stable for analysis for about 15 minutes.

Electrophoretic mobility $u_{e}$ was measured at $25 \pm 0.1^{\circ} \mathrm{C}$ using a Malvern Zetasizer Nano ZS with disposable cuvettes Malvern DTS1060. These were used because the application of the solvent resistant dip cell provided by Malvern resulted in a degradation of the toluene and / or the palladium electrodes to dark brown residua during measurements. Even though the disposable cuvettes were blurred by the toluene after several runs, equivalent results could be gained reusing these cuvettes and the results of Marinova et al. (1996) could be reproduced. Additionally, the phase fraction of toluene of the investigated emulsion was below $0.1 \%$, which minimises the chance of a dissociation of contaminants from the disposable cuvettes by toluene during the short time of measurement (approximately 30 seconds). For every pH value at least two separate samples were prepared and measured in several runs each, resulting in approx. 30 - 60 single measurement runs per $\mathrm{pH}$ value. The 'general purpose' mode of Malvern Zetasizer Nano ZS was used, thus every value from a single measurement run represents the mean value of the zeta potential distribution.

\subsection{Numerical investigations \& parameter estimation}

In this study the experimental drop size distributions in a stirred tank were simulated using an integral single zone PBE of the whole tank with a mean energy input $\epsilon$ generated by the impeller. The volume-related PBE for this batch reactor describing the time dependent number density function $f\left(d_{p}, t\right)$ of drops with diameter $d_{p}$ becomes (Attarakih et al., 2004; Gäbler et al., 2006; Liao and Lucas, 2009):

$$
\begin{aligned}
\frac{\partial f\left(d_{p}, t\right)}{\partial t}=\int_{d_{p}}^{d_{p, \max }} n_{d}\left(d_{p}^{\prime}\right) \cdot \beta\left(d_{p}, d_{p}^{\prime}\right) \cdot g\left(d_{p}^{\prime}\right) \cdot f\left(d_{p}^{\prime}, t\right) \mathrm{d} d_{p}^{\prime}-g\left(d_{p}\right) \cdot f\left(d_{p}, t\right) \\
\quad+\frac{1}{2} \int_{0}^{d_{p}} \xi\left(d_{p}^{\prime \prime}, d_{p}^{\prime}\right) \cdot \lambda\left(d_{p}^{\prime \prime}, d_{p}^{\prime}\right) \cdot f\left(d_{p}^{\prime}, t\right) \cdot f\left(d_{p}^{\prime \prime}, t\right) \mathrm{d} d_{p}^{\prime} \\
-f\left(d_{p}, t\right) \cdot \int_{0}^{d_{p, \max }-d_{p}} \xi\left(d_{p}, d_{p}^{\prime}\right) \cdot \lambda\left(d_{p}, d_{p}^{\prime}\right) \cdot f\left(d_{p}^{\prime}, t\right) \mathrm{d} d_{p}^{\prime}
\end{aligned}
$$


consisting of the number of daughter droplets $n_{d}$, daughter drop size distribution $\beta\left(d_{p}, d_{p}^{\prime}\right)$, breakage rate $g\left(d_{p}\right)$, collision frequency $\xi\left(d_{p}, d_{p}^{\prime}\right)$ and coalescence efficiency $\lambda\left(d_{p}, d_{p}^{\prime}\right)$ and using the definition $d_{p}^{\prime \prime}=\left(d_{p}^{3}-d_{p}^{\prime 3}\right)^{1 / 3}$. The detailed description of the PBE, the sub model implementation and numerical parameter definition is reported in Kamp et al. (2012). As this article focusses on the coalescence efficiency, the other sub models of collision frequency and drop breakage which are necessary to solve the PBE were taken from the frequently used model of Coulaloglou and Tavlarides (1977). The coalescence efficiency sub models of Coulaloglou and Tavlarides (1977) and Tobin and Ramkrishna (1999) were compared with regard to the description of the coalescence inhibition due to electrostatic effects. Furthermore, a new coalescence efficiency sub model was developed in order to describe this inhibition properly. Concerning the droplet breakup, an effective daughter drop size distribution should have no singularities and fall to zero as the ratio between mother and daughter drop diameter becomes zero or one (Maaß et al., 2007; Wang et al., 2003; Zaccone et al., 2007). Otherwise, a droplet breakup would cause a loss of mass and violate the mass balance. Since the daughter drop size distribution of the Coulaloglou and Tavlarides (1977) model is implemented as a normal distribution, it does not fulfil the mentioned requirements. Thus, a relatively narrow normal distribution was applied for the binary droplet breakup (number of daughter droplets $n_{d}=2$ ) of a droplet with volume $V_{p}$ : a mean daughter drop volume $V_{\mu}=\frac{V_{p}}{n_{d}}$ and a standard deviation of $V_{\sigma}=\frac{V_{p}}{5 n_{d}}$ was used. Using these parameters $>99.9 \%$ of droplets formed lay within the volume range from 0 to $V_{p}$ and the mass balance could be conserved adequately.

The commercial software PARSIVAL ${ }^{\circledR}$ (Wulkow et al., 2001) was used to solve the partial differential equation of the PBE with coupled mass balance.

The numerical parameters of the breakage and coalescence rate of the different models were fitted to experimental data using the implemented parameter estimation routine by minimising the residual between experimental and simulated data. To quantify this residual between $n$ experimental values $X_{i}$ and calculated ones $\hat{X}_{i}$, the root-mean-square deviation (RMSD) was used in this work:

$$
\operatorname{RMSD}(X)=\sqrt{\frac{\sum_{i=1}^{n}\left(X_{i}-\hat{X}_{i}\right)^{2}}{n}} .
$$

At the beginning, all parameters of the basic Coulaloglou and Tavlarides (1977) model were optimized to the transient development of the Sauter mean diameter $d_{32}$ at $\mathrm{pH}$ 7. To provide comparability between the models, these fitted parameters for drop breakage $\left(c_{1, b}\right.$ and $\left.c_{2, b}\right)$ and collision frequency $\left(c_{1, c}\right)$ were kept constant throughout the whole study. For the coalescence efficiency sub model(s) the corresponding 'hydrodynamic' parameter $c_{2, c}$ was also adapted to $\mathrm{pH} 7$ and the 'electrostatic' parameter $c_{3, c}$ was adjusted to transient data of $d_{32}$ at pH 13. All parameters are given in SI units if dimensional: $c_{2, c}$ of the Coulaloglou and Tavlarides (1977) model has the dimension $\left[\mathrm{m}^{-2}\right.$ ] and $c_{3, c}$ of the Tobin and Ramkrishna (1999) model is not dimension consistent and would have the dimension $[\mathrm{N} / \mathrm{m}]$ and/or $\left[\mathrm{N} / \mathrm{m}^{2}\right]$. For detailed information of the model implementation and numerical parameter definition see Kamp et al. (2012).

All simulations were verified to be independent from the initial drop size distribution after a few seconds or iteration steps, respectively. Thus, a Gaussian initial drop size distribution with a mean value $d_{\mu}=1 \mathrm{~mm}$ and standard deviation $d_{\sigma}=50 \mu \mathrm{m}$ was used arbitrarily.

The interfacial tension was set to $\gamma=35 \mathrm{mN} / \mathrm{m}$ for all simulations with $\mathrm{pH}<12.5$. For $\mathrm{pH}>12.5$ $\gamma=32 \mathrm{mN} / \mathrm{m}$ was used according to the measurements performed by Kamp et al. (2012). Anyhow, the influence of the change in interfacial tension is rather small in the simulations: the reduction from $\gamma=35 \mathrm{mN} / \mathrm{m}$ to $32 \mathrm{mN} / \mathrm{m}$ leads to a decrease of the steady state Sauter mean diameter of approximately $d_{32, \text { stat }} \approx 15 \mu \mathrm{m}$. 


\section{Results \& discussion}

As already pointed out in the introduction, the origin of the surface potential in liquid/liquid systems is discussed controversially in literature until present. However, a description and quantification of the surface potential is inevitable to implement the DLVO theory into the population balance equation. Hence, the following approach was chosen: the ions were assumed to accumulate at (or near) the interface and the anions $\mathrm{OH}^{-}$and $\mathrm{Cl}^{-}$were identified to be potential determining. The accumulation of these ions was described by a Stern isotherm for which the surface potential was investigated by zeta potential measurements. This approach is presented and discussed in the following and then used to develop the coalescence model which is compared with existing models in literature.

\subsection{Zeta potential investigations}

The electrophoretic mobility $u_{e}$ was measured varying the $\mathrm{pH}$ value from $\mathrm{pH}=2$ to 13 at constant ionic strength of $I=0.1 \mathrm{~mol} / \mathrm{L}$ according to the procedure described in section 2.2 . With the measured drop radius of $a=2.5 \mu \mathrm{m}$, the resulting $\kappa a=259$ fulfils the restriction of the HelmholtzSmoluchowski equation ( $\kappa \cdot a>>1$ ) (Delgado et al., 2007; Smoluchowski, 1903). Thus, zeta potential was calculated from electrophoretic mobility originally measured by the Zetasizer Nano ZS, although the Helmholtz-Smoluchowski equation is applicable only for rigid particles. Nevertheless, it is used because the presence of the double layer is assumed to result in a reduced momentum transfer to the drop phase according to Delgado et al. (2007). Likewise, Lyklema (2000) regards the neglect of a mobile interface as more appropriate for liquid/liquid than for gas/liquid interfaces which is obvious having a viscosity change in the order of several magnitudes from gas to oil. The measured electrophoretic mobility and the calculated zeta potential over the $\mathrm{pH}$ range are shown in Figure 1. The vertical error bars represent the standard deviation between all measured values. The highest deviation in the measured zeta potential was measured in the sample with $\mathrm{pH}$ between 9 and 10. However, this data point seems to be an outlier in Figure 1. The horizontal error bars indicate the standard deviation of the $\mathrm{pH}$ values measured in the serial dilutions and samples at different times. Especially the samples prepared with ion concentrations resulting in $\mathrm{pH}$ values from 6 to 10 show a shift to lower $\mathrm{pH}$ value due to absorption of carbon dioxide from the atmosphere and therefore result in $\mathrm{pH}$ deviations. However, the presence of carbon dioxide in the continuous water phase due to absorption did not have an observable effect on the zeta potential which was also reported by Marinova et al. (1996). At very acidic conditions the $\mathrm{pH}$ deviation becomes so small that the error bars are covered by the symbols. 


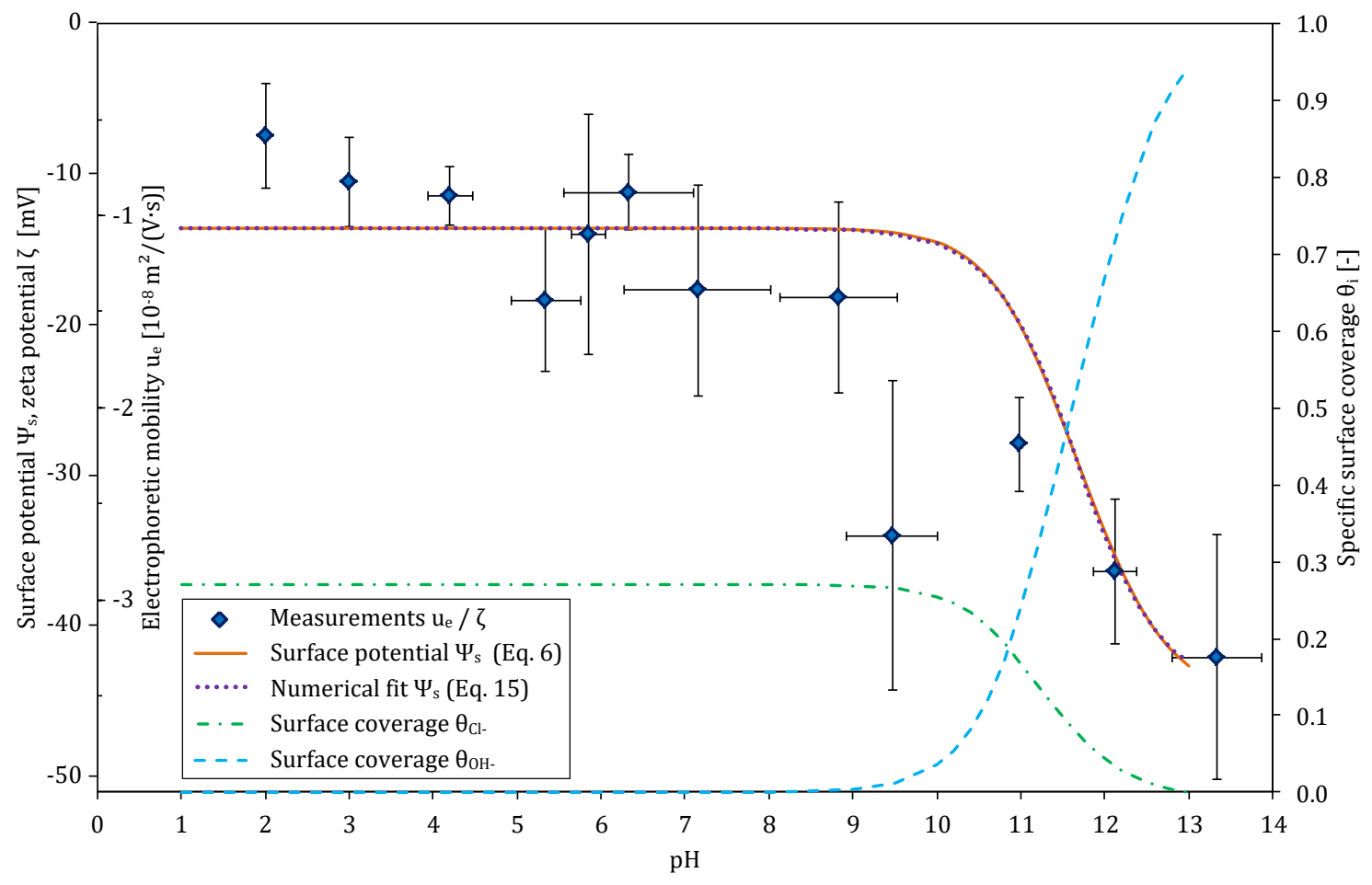

Figure 1: Zeta potential and electrophoretic mobility over $\mathrm{pH}$ value, the specific surface coverage of $\mathrm{Cl}^{-}$and $\mathrm{OH}^{-}$ (Equation 5) from the adsorption isotherm (Equation 3) and the corresponding surface potential $\Psi_{s}$ (Equation 6) and its numerical fit (Equation 15) at constant ionic strength $I=0.1 \mathrm{~mol} / \mathrm{L}$ in toluene/water system.

The zeta potential was found to scatter around a constant value of about $-15 \mathrm{mV}$ for $\mathrm{pH}<9$, which can be explained by the adsorption of $\mathrm{Cl}^{-}$at (or near) the interface. For higher $\mathrm{pH}$ values a strong decrease of the zeta potential down to $-42 \mathrm{mV}$ was found which corresponds to the replacement of $\mathrm{Cl}^{-}$with $\mathrm{OH}^{-}$ions due to the higher bulk concentration of hydroxide. The specific coverages of the

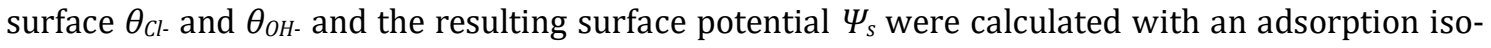
therm and the Grahame equation as described in the following and are shown in Figure 1.

According to Marinova et al. (1996) and Derjaguin et al. (1987), the ion accumulation is described by a Stern adsorption isotherm (Derjaguin, 1989; Stern, 1924):

$$
\Gamma_{\mathrm{i}}=\frac{\Gamma_{0} v_{i} n_{i, 0} \exp \left(-\frac{\Phi_{i}+z_{i} e \Psi_{\mathrm{s}}}{k_{B} T}\right)}{1+\sum_{i} v_{i} n_{i, 0} \exp \left(-\frac{\Phi_{i}+z_{i} e \Psi_{\mathrm{s}}}{k_{B} T}\right)}
$$

where $\Gamma_{i}$ is the number of type $i$ ions per surface area which is described by the ion specific parameters: $v_{i}$ the volume of a hydrated ion, $n_{i, 0}$ the number concentration in bulk, $z_{i}$ the valence; the physical constants: $e$ the elementary charge and $k_{B}$ the Boltzmann constant; the system specific parameters: surface potential $\Psi_{S}$, temperature $T$ and the fitted parameters: $\Gamma_{0}$ the referenced saturation adsorption, $\Phi_{i}$ the specific interaction energy of ion $i$. The Stern isotherm becomes a Langmuir isotherm for $z_{i}=0$. In this study not only the adsorption of $\mathrm{OH}^{-}$was considered as done by Marinova et al. (1996) but additionally the adsorption of $\mathrm{Cl}^{-}$to describe the low potentials of about $-15 \mathrm{mV}$ for $\mathrm{pH}<9$. The relation between the surface charge density $\sigma$ and the surface potential $\Psi_{s}$ is given by the Grahame equation (Butt et al., 2003; Israelachvili, 1991):

$$
\sigma=\sqrt{8 \varepsilon_{r} \varepsilon_{0} k_{B} T n_{\text {salt }, 0}} \sinh \left(\frac{e \Psi_{s}}{2 k_{B} T}\right)
$$

where $\varepsilon_{r}$ is the relative and $\varepsilon_{0}$ the vacuum permittivity and $n_{\text {salt }, 0}$ the number concentration of the salts in the bulk. In the case of monovalent ions $n_{\text {salt }, 0}$ is equivalent to the number concentration of 
the dissolved anions (or cations) or the ionic strength times the Avogadro constant: $I \cdot N_{A}$. It is assumed here that the surface potential $\Psi_{s}$ is determined by the anions $\mathrm{OH}^{-}$and $\mathrm{Cl}^{-}$and that it is equal to the zeta potential. The surface coverage of an adsorbed ion $i$ is derived from the Stern adsorption isotherm (Equation 3):

$$
\theta_{i}=\frac{\Gamma_{i}}{\Gamma_{0}} .
$$

Additionally, the total charge induced by the ion coverage $\left(\sum_{i} z_{i} e \theta_{i}\right)$ has to equal the surface charge density given by the Grahame equation (Equation 4) (Marinova et al., 1996):

$$
-e\left(\theta_{\mathrm{OH}^{-}}+\theta_{C l^{-}}\right)=\sigma \text {. }
$$

To obtain the graph shown in Figure 1, both sides of the Equation 6 were solved iteratively using the least-squares method to identify the surface potential $\Psi_{s}$ with varying $\mathrm{pH}$ and thus specific ion concentrations. To fit the zeta potential measurements the values of the saturation adsorption $\Gamma_{0}=2.3185 \cdot 10^{17} \mathrm{~m}^{-2}$ and the specific interaction energies $\Phi_{O H-}=-9.50 \mathrm{k}_{\mathrm{B}} \cdot \mathrm{T}$ and $\Phi_{C l}=-4.25 \mathrm{k}_{\mathrm{B}} \cdot \mathrm{T}$ were determined manually in the Stern isotherm. The volumes of the hydrated ions were implemented as $v_{O H-}=1.1 \cdot 10^{-28} \mathrm{~m}^{3}$ (Israelachvili, 1991) and $v_{\mathrm{Cl}}=1.5 \cdot 10^{-28} \mathrm{~m}^{3}$ (David et al., 2001; Israelachvili, 1991). According to the results of Tian and Shen (2009), the adsorption of $\mathrm{OH}^{-}$was found to be preferential against $\mathrm{Cl}$. Additionally, the surface coverage of $\mathrm{Cl}^{-}$is located in the same range $\left(\theta_{C l}=0.20\right)$ as in our case $\left(\theta_{C l}=0.27\right)$. Moreover, the measured increase of the zeta potential for $\mathrm{pH}<3$ (see Figure 1) could be explained by the additional adsorption of $\mathrm{H}_{3} \mathrm{O}^{+}$under these conditions which was found by Tian and Shen (2009). As this influence is rather small and not significant in this case, it is not modelled here.

Despite the previously discussed limitations of this measurement technique, the zeta potential is a feasible technique to gain at least qualitative influences on the surface potential and thus on the emulsion stability (Lyklema, 2000; Marinova et al., 1996; Rambhau, 1978), although the measured value may not be equal with the existent surface potential (however it is induced) (Delgado et al., 2007).

The use of a Gibbs isotherm may be more appropriate in the case of liquid/liquid systems (Lyklema, 2000), but significant surface tension measurements were not available. A decrease in the surface tension from $\gamma=35$ to $32 \mathrm{mN} / \mathrm{m}$ was found as reported in Kamp et al. (2012), but the standard deviation increased considerably at high pH. Additionally, Derjaguin et al. (1987) discussed the consideration of Gibbs free energy and a formation of a double layer at both sides of the interface (in oil and water phase respectively) and thus obtained the same functional relation for the electrostatic force as in the case of Stern adsorption. However, the Stern isotherm is used to describe the trend of the zeta potential over $\mathrm{pH}$ value which is again simplified by a numerical fit in the developed model due to a reduction of computation time (see chapter 3.2.2). Thus, the described approach is regarded as adequate.

\subsection{Modelling \& simulation}

This section begins with an application of the coalescence efficiency sub models of Coulaloglou and Tavlarides (1977) and Tobin and Ramkrishna (1999) to the coalescence inhibition found at high pH values. Afterwards, the new modelling approach is developed and discussed.

\subsubsection{Simulations with existing models}

As discussed in detail in Kamp et al. (2012), the model of Coulaloglou and Tavlarides (1977) is able to describe the experimental data by varying only the numerical parameter $c_{2, c}$ of the coalescence efficiency. These findings are presented shortly in the following with the difference to Kamp et al. (2012) that no additional prefactor of the energy dissipation rate was used $\left(f_{\epsilon}=1\right)$ as suggested in Kamp et al. (2012). This prefactor was formerly considered to account for inhomogeneous energy 
dissipation within the stirred tank. The values of the used parameters can be found in Table 2. As can be seen in Figure 2 (left), the transient simulation predicts the development of the Sauter mean diameter $d_{32}$ well. On the right hand side of Figure 2 the arithmetic mean of the $d_{32}$ values after reaching the steady state is plotted against the corresponding $\mathrm{pH}$ value. The vertical error bars indicate the standard deviation between these stationary $d_{32, \text { stat }}$ values of each transient measurement. As the model of Coulaloglou and Tavlarides (1977) does not depend on $\mathrm{pH}$, the simulated $d_{32, s t a t}$ are constant as long as the numerical parameters are. For the simulation at $\mathrm{pH} 13$ the parameter $c_{2, c}$ was adapted to experimental values at $\mathrm{pH} 13$ and used for this simulation (see Table 2). Between pH 12 and 13 the graph is interpolated linearly in this representation, although for every experiment in this region the parameter $c_{2, c}$ would have to be fitted respectively. The root-meansquare deviation of the stationary Sauter mean diameters $d_{32, \text { stat }}$ between all experimentally investigated $\mathrm{pH}$ values and the simulated ones results in $\operatorname{RMSD}\left(d_{32, s t a t}\right)=28.41 \mu \mathrm{m}$. The RMSD for the three stirrer speeds are given in Table 1.
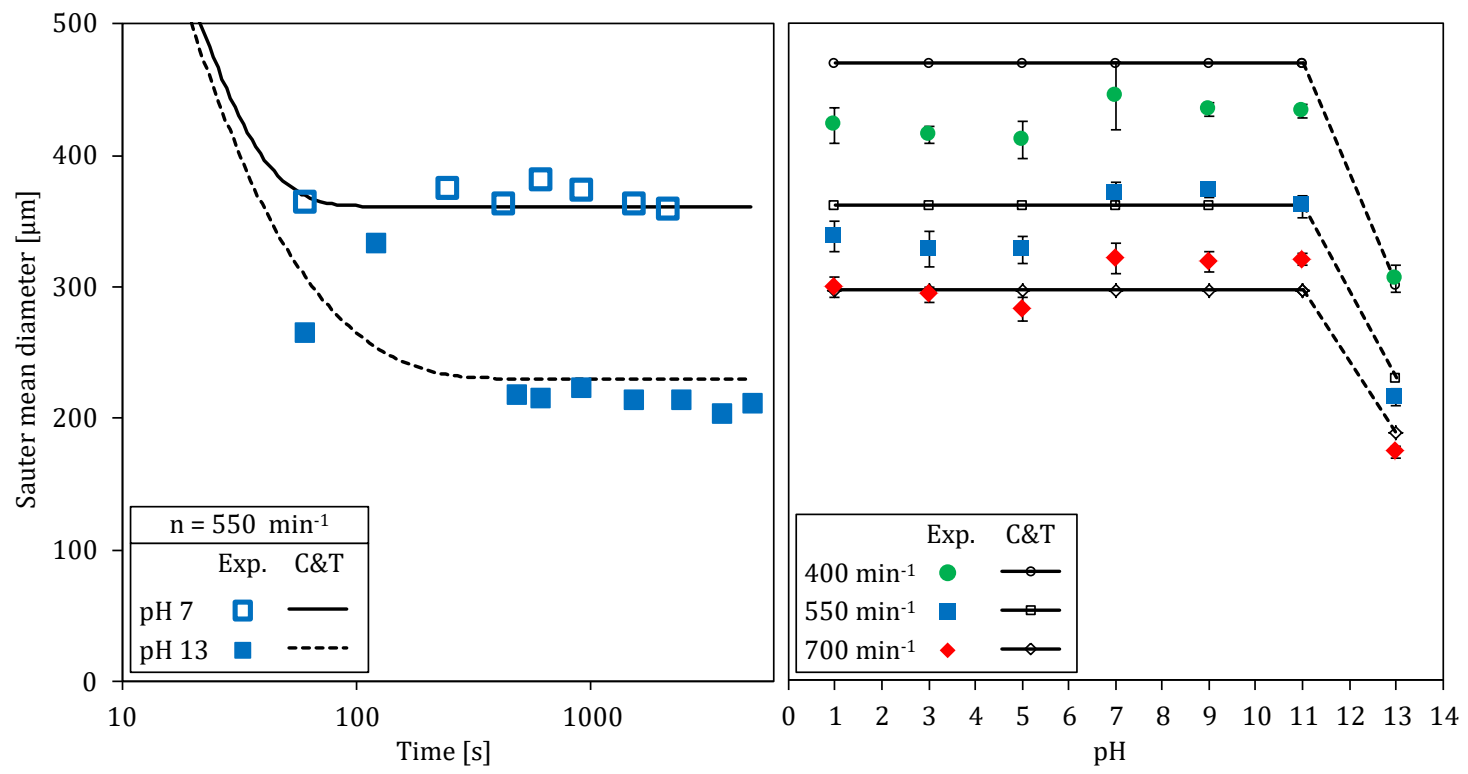

Figure 2: Simulations using the Coulaloglou and Tavlarides (1977) model (C\&T) in comparison with experimental data. Left: transient Sauter mean diameter $d_{32}$ at $n=550 \mathrm{~min}^{-1}$, right: stationary $d_{32, \text { stat }}$ vs. pH of continuous phase.

Tobin and Ramkrishna (1999) introduced an additional numerical parameter $c_{3, c}$ to describe the coalescence inhibition due to electrostatic effects. Unfortunately, this model does not describe the experimental data better than the Coulaloglou and Tavlarides (1977) model, which can be seen in Figure 3. This can be quantified by the root-mean-square deviation of $d_{32, \text { stat }}$ which results in $\operatorname{RMSD}\left(d_{32, s t a t}\right)=51.12 \mu \mathrm{m}$. This is nearly twice the value of the Coulaloglou and Tavlarides (1977) model. The RMSD for the three stirrer speeds are given in Table 1. Moreover, the parameter $\mathrm{c}_{3, \mathrm{c}}$ has to be fitted to the experimental data with varying $\mathrm{pH}$ just as done in the Coulaloglou and Tavlarides (1977) model with parameter $c_{2, c}$. Again, the range between $\mathrm{pH} 12$ and 13 is interpolated linearly in the graph, because only two values for $c_{3, c}$ were fitted: for $\mathrm{pH} 1$ - 12 and pH 13 (see Table 2). Hence, this model does not achieve an improvement of the prediction quality and moreover causes some numerical problems in the implementation as described in Kamp et al. (2012). 

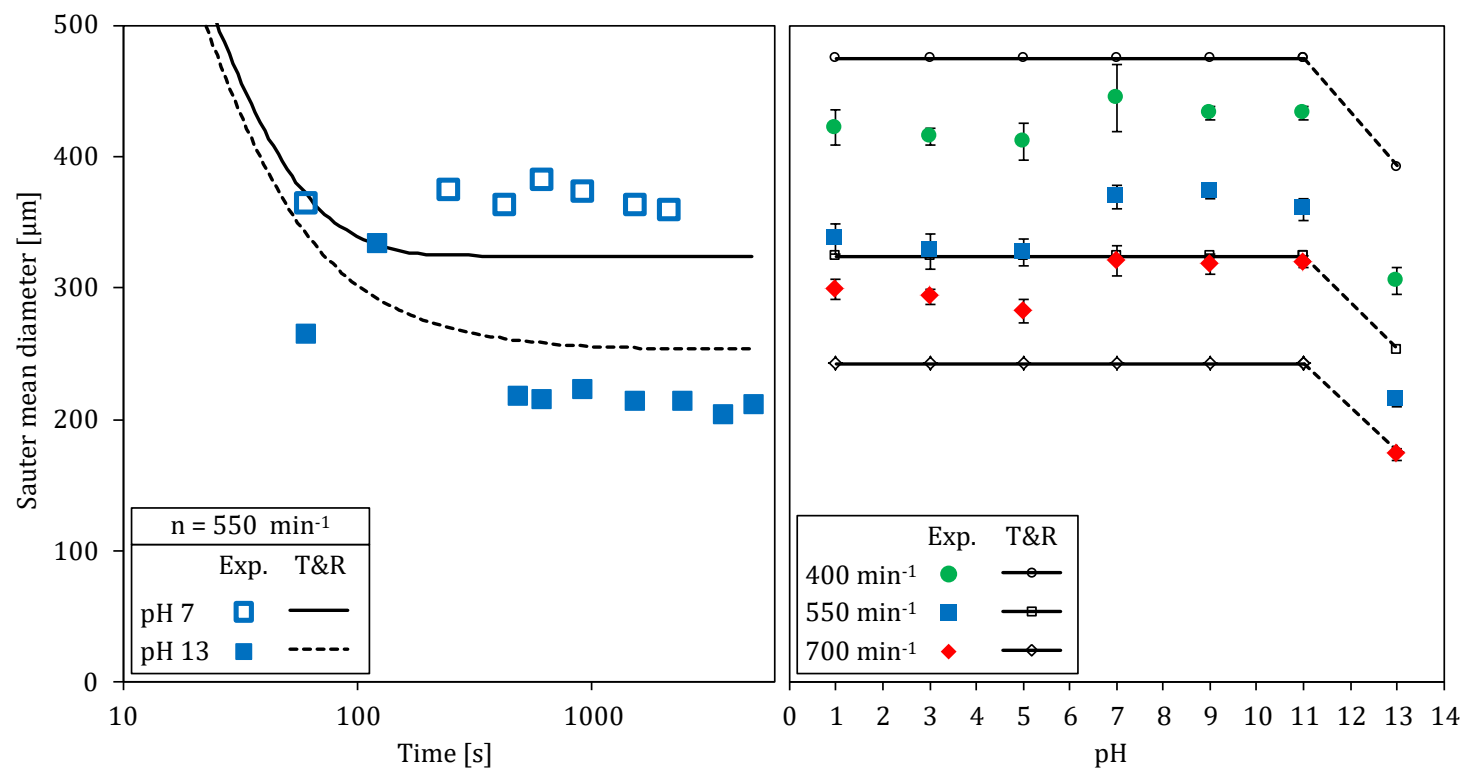

Figure 3: Simulations using the Tobin and Ramkrishna (1999) model $(T \& R)$ in comparison with experimental data. Left: transient Sauter mean diameter $d_{32}$ at $n=550 \mathrm{~min}^{-1}$, right: stationary $d_{32, \text { stat }}$ vs. pH of continuous phase.

Table 1: Root-mean-square deviations of stationary Sauter mean diameters from simulations using Coulaloglou and Tavlarides (1977) (C\&T) and Tobin and Ramkrishna (1999) (T\&R) model vs. pH.

\begin{tabular}{lllll}
\hline stirrer frequency $\boldsymbol{n}$ & $\mathbf{4 0 0} \mathbf{~ m i n}^{-1}$ & $\mathbf{5 5 0} \mathbf{~ m i n}-\mathbf{1}$ & $\mathbf{7 0 0} \mathbf{~ m i n}^{-1}$ & total \\
\hline $\operatorname{RMSD}\left(d_{d 32, s t a t}\right) \mathrm{C} \& \mathrm{~T}$ & $40.73 \mu \mathrm{m}$ & $21.64 \mu \mathrm{m}$ & $17.13 \mu \mathrm{m}$ & $28.41 \mu \mathrm{m}$ \\
$\operatorname{RMSD}\left(d_{d 32, s t a t}\right) \mathrm{T} \& \mathrm{R}$ & $56.79 \mu \mathrm{m}$ & $32.17 \mu \mathrm{m}$ & $59.84 \mu \mathrm{m}$ & $51.12 \mu \mathrm{m}$ \\
\hline
\end{tabular}

Table 2: Numerical parameters of used sub models in PBE.

\begin{tabular}{llllll}
\hline Coalescence efficiency model & $\boldsymbol{c}_{\boldsymbol{1}, \boldsymbol{b}}$ & $\boldsymbol{c}_{2, \boldsymbol{b}}$ & $\boldsymbol{c}_{1, \boldsymbol{c}}$ & \multicolumn{1}{c}{$\boldsymbol{c}_{2, \boldsymbol{c}}$} & \multicolumn{1}{c}{$\boldsymbol{c}_{3, \boldsymbol{c}}$} \\
\hline Coulaloglou \& Tavlarides (1977) pH 7 & & & & $3.8591 \cdot 10^{13}$ & - \\
Coulaloglou \& Tavlarides (1977) pH 13 & & & & $2.7597 \cdot 10^{14}$ & - \\
Tobin \& Ramkrishna (1999) pH 7 & $4.8701 \cdot 10^{-3}$ & $5.5199 \cdot 10^{-2}$ & $1.1878 \cdot 10^{-1}$ & $3.3424 \cdot 10^{-4}$ & $1.0 \cdot 10^{-9}$ \\
Tobin \& Ramkrishna (1999) pH 13 & & & & $3.3424 \cdot 10^{-4}$ & $1.2 \cdot 10^{0}$ \\
own DLVO model pH 1 - 13 & & & & $3.8591 \cdot 10^{13}$ & $2.0618 \cdot 10^{3}$ \\
\hline
\end{tabular}

\subsubsection{Development of electrostatic DLVO model}

The above discussed results of existent models were the motivation to develop a new model for population balance equations, which implements the interaction forces of the DLVO theory and is adaptable with one constant numerical parameter. Moreover, the model was developed considering the modular concept of the population balance. Thus, the new approach was reduced to describe only the coalescence efficiency caused by the electrostatic double layer force and use it as an extension for existent models which mainly depict hydrodynamic interactions between two colliding droplets. Hence, the coalescence probability caused by hydrodynamic interactions can be described by any of the available models in literature, e.g. the model of Coulaloglou and Tavlarides (1977) 
(which explicitly excludes the van der Waals and double layer forces). Regarding the two coalescence inhibition processes (hydrodynamic and electrostatic) as independent from one another, the total coalescence efficiency becomes:

$$
\lambda=\lambda_{\text {hydrodynamic }} \cdot \lambda_{\text {DLVO }} \cdot
$$

Following this modelling approach, the electrostatic coalescence inhibition can be implemented easily in simulations if necessary.

The implementation of the DLVO interactions follows the functional approach of Coulaloglou and Tavlarides (1977). They assume that the coalescence occurs if the contact time exceeds the time which is needed until the thin film of continuous phase between the drops is drained. Assuming the contact time being a normally distributed random variable, these counteracting times determine the coalescence probability by the functional approach:

$$
\lambda_{\mathrm{C \& T}} \propto \exp \left(-\frac{t_{\text {drainage }}}{t_{\text {contact }}}\right) .
$$

In the case of DLVO interactions, the counteracting repulsive electrostatic double layer force $F_{e l}$ and attractive van der Waals force $F_{v d W}$ depend on the distance $h$ between two approaching droplets. This distance and therefore the two forces vary with the contact time of two droplets and are assumed to be normally distributed random variables. Hence, the same functional approach is used to describe the electrostatic coalescence probability depending on the ratio between $F_{e l}$ and the absolute value of $F_{v d w \text { : }}$

$$
\lambda_{D L V O} \propto \exp \left(-\frac{F_{e l}}{\left|F_{v d W \mid}\right|}\right) .
$$

Considering the approach of Derjaguin (1934) to calculate these forces for curved surfaces, the electrostatic double layer force for two approaching droplets is given for symmetrical electrolytes by Derjaguin et al. (1987) and Miller and Neogi (2008):

$$
F_{e l}=32 \pi \varepsilon_{0} \varepsilon_{r} \kappa R_{e q}\left(\frac{k_{B} T}{z e}\right)^{2} \tanh ^{2}\left(\frac{\mathrm{ze} \Psi_{s}}{4 k_{B} T}\right) \exp (-\kappa h)
$$

assuming the surface potential being constant during approach, where $R_{e q}$ is the equivalent drop radius of the two approaching droplets with the diameters $d_{1}$ and $d_{2}$ :

$$
R_{e q}=\frac{d_{1} \cdot d_{2}}{d_{1}+d_{2}}
$$

$h$ the minimal distance between them and $\kappa^{1}$ the Debye length

$$
\kappa^{-1}=\left(\frac{\sum_{i} e^{2} z_{i}^{2} n_{i, 0}}{\varepsilon_{0} \varepsilon_{r} k_{B} T}\right)^{-\frac{1}{2}}
$$

considering the charge number $z_{i}$ and number concentration $n_{i, 0}$ of all ion species in the system. The Debye length $\kappa^{1}$ is the characteristic decay length of the surface potential due to the diffuse ion layer around the charged droplet and depends solely on the properties of the continuous phase (Israelachvili, 1991). The calculation of $F_{e l}$ for asymmetrical electrolytes is discussed and described in Derjaguin et al. (1987) and a straightforward implementation of these equations can be done if necessary.

The attractive van der Waals force for spherical particles was calculated by Hamaker (1937) and becomes (Butt et al., 2003; Israelachvili, 1991):

$$
F_{v d W}=-\frac{\pi^{2} A_{1,2,3}}{12 h^{2}} R_{e q}
$$

where $A_{1,2,3}$ is the Hamaker constant (which is occasionally defined as: $A_{1,2,3}^{\prime}=\pi^{2} \cdot A_{1,2,3}$ in several references).

Implementing the equations 10 - 13 into equation 9 and merging all constants into the numerical parameter $c_{3, c}$, the electrostatic coalescence probability becomes:

$$
\lambda_{D L V O}=\exp \left(-c_{3, c} \frac{\varepsilon_{0} \varepsilon_{r} \kappa h^{2}}{A_{1,2,3}}\left(\frac{k_{B} T}{z e}\right)^{2} \tanh ^{2}\left(\frac{\mathrm{ze} \Psi_{s}}{4 k_{B} T}\right) \exp (-\kappa h)\right) .
$$


The derived electrostatic coalescence probability is independent of the drop sizes which is favourable as the influence of the drop size is already implemented in hydrodynamic models. The coalescence probability $\lambda_{D L V O}$ depends on the physical properties of the system which are typically known, the distance between the droplets $h$ and the surface potential $\Psi_{s}$.

As most applications of the population balance equation use an integral balance of the simulated volume (the entire liquid volume of the stirred tank in this case), the detailed information of drop trajectories and thus distances is not available. Hence, critical distances are introduced in several models, e.g. the critical film rupture thickness in film drainage models (Liao and Lucas, 2010). As the distance of the characteristic maximum (and minimum) of the resulting DLVO force $\left(F_{e l}+F_{v d W}\right)$ varies especially with the electrolyte concentration (Israelachvili, 1991; Pfennig and Schwerin, 1998) (see Figure 4), an assumption of a constant drop distance would be misleading. Therefore, the distance $h$ is implemented in integral simulations as the Debye length $\kappa^{1}$, because it is determined solely by the composition of the electrolyte solution and also describes a characteristic length concerning the electrostatic interactions.
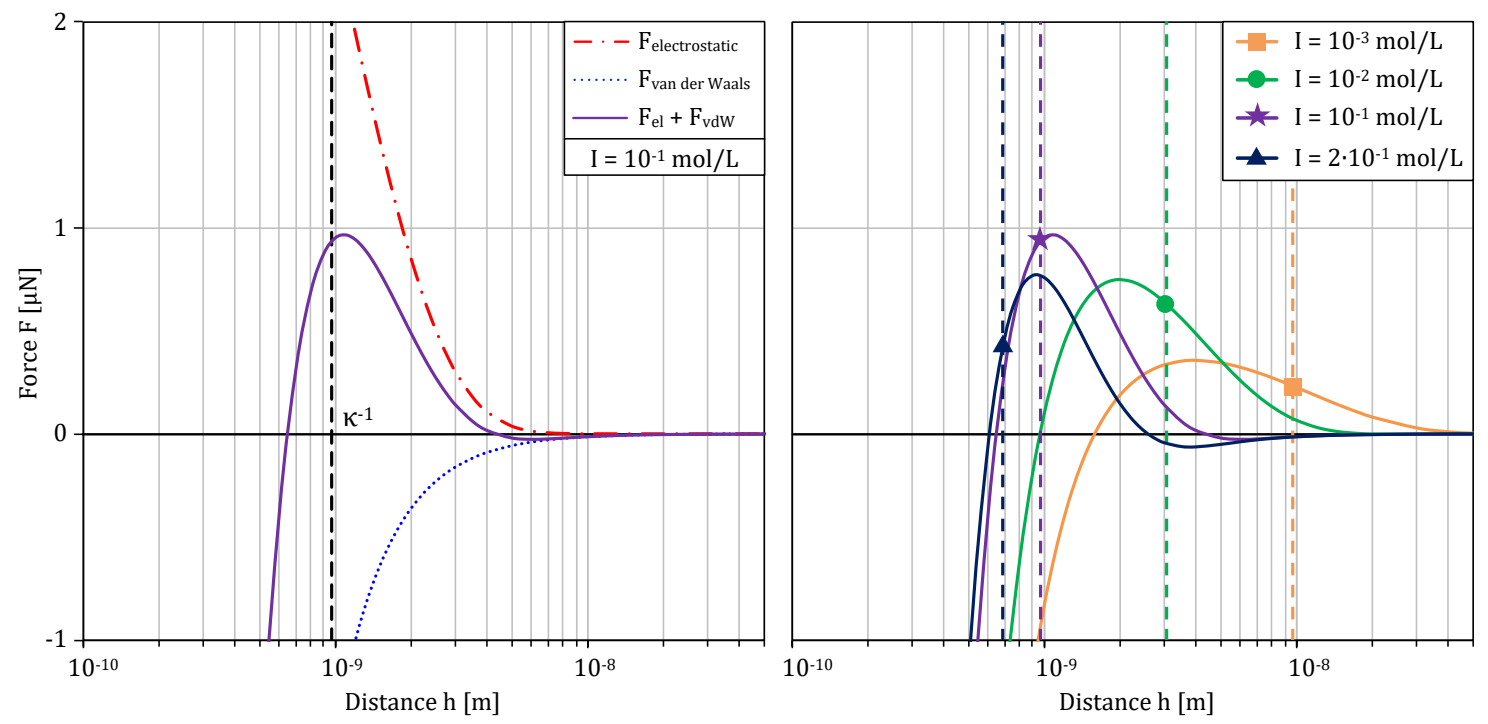

Figure 4: Left: representation of the opposing forces $\mathrm{F}_{\mathrm{el}}$ and $\mathrm{F}_{\mathrm{vdw}}$ and the resulting DLVO force vs. the distance $h$ of two toluene drops $\left(d=500 \mu \mathrm{m}, \Psi_{s}=100 \mathrm{mV}\right)$ in an aqueous electrolyte solution ( $\left.\mathrm{I}=0.1 \mathrm{~mol} / \mathrm{L}\right)$ and the corresponding Debye length $\kappa^{1}$. Right: resulting DLVO force and corresponding Debye length $\kappa^{1}$ with variation of the ionic strength $I$. (Corrected erratum: $\mathrm{I}=2 \cdot 10^{-1} \mathrm{~mol} / \mathrm{L}$ in legend)

The surface potential was described using the calculated zeta potential by Stern isotherm and Grahame equation from the zeta potential measurements as specified in section 3.1. To avoid the frequent iterative calculation of these two equations in terms of a minimization of computation time, the development of the zeta potential versus the $\mathrm{pH}$ value was fitted by the numerical equation:

$$
\Psi_{s}[\mathrm{mV}]=a \cdot \tanh (p H+b)+c
$$

using the parameters $a, b$ and $c$ listed in Table 3 . The fit is accurate with a root-mean-square deviation of RMSD $(\Psi \mathrm{s})=0.09593 \mathrm{mV}$.

Table 3: Numerical parameters (including 95\% confidence bounds) of the numerical fit for the surface potential $\Psi$ s.

\begin{tabular}{lll}
\hline $\boldsymbol{a}[\mathbf{m V}]$ & $\boldsymbol{b}[-]$ & $\boldsymbol{c}[\mathbf{m V}]$ \\
\hline$-15.44(-15.52,-15.37)$ & $-11.67(-11.66,-11.68)$ & $-29.00(-29.08,-28.91)$ \\
\hline
\end{tabular}




\subsubsection{Simulations with DLVO model}

To describe the experimental data properly, the 'hydrodynamic' Coulaloglou and Tavlarides (1977) coalescence efficiency $\lambda_{C \& T}$ was extended with the developed DLVO coalescence efficiency $\lambda_{D L V O}$ according to Equation 7:

$$
\lambda=\lambda_{C \& T} \cdot \lambda_{D L V O}
$$

The determined numerical parameters from the Coulaloglou and Tavlarides (1977) model at pH 7 were used and not changed, only the parameter $c_{3, c}$ was fitted to the experimental data at $\mathrm{pH} 13$ as shown in Table 2. The Hamaker constant for the interaction between two toluene phases in water $A_{T, W, T}=7.02 \cdot 10^{-21} \mathrm{~J}$ was calculated using data from Rosenholm (2010).

As can be seen in Figure 5, these simulations describe the experimental data and especially the coalescence inhibition at $\mathrm{pH} 13$ well with a root-mean-square deviation of the stationary Sauter mean diameter $\operatorname{RMSD}\left(d_{32, s t a t}\right)=24.67 \mu \mathrm{m}$, which is the lowest deviation of all three investigated models. The RMSD for the three stirrer speeds are given in Table 4. For these simulations only constant numerical parameters were used over the whole $\mathrm{pH}$ range (see Table 2). It is obvious that the calculated stationary $d_{32, \text { stat }}$ follows the trend of the zeta potential with the $\mathrm{pH}$ shift.
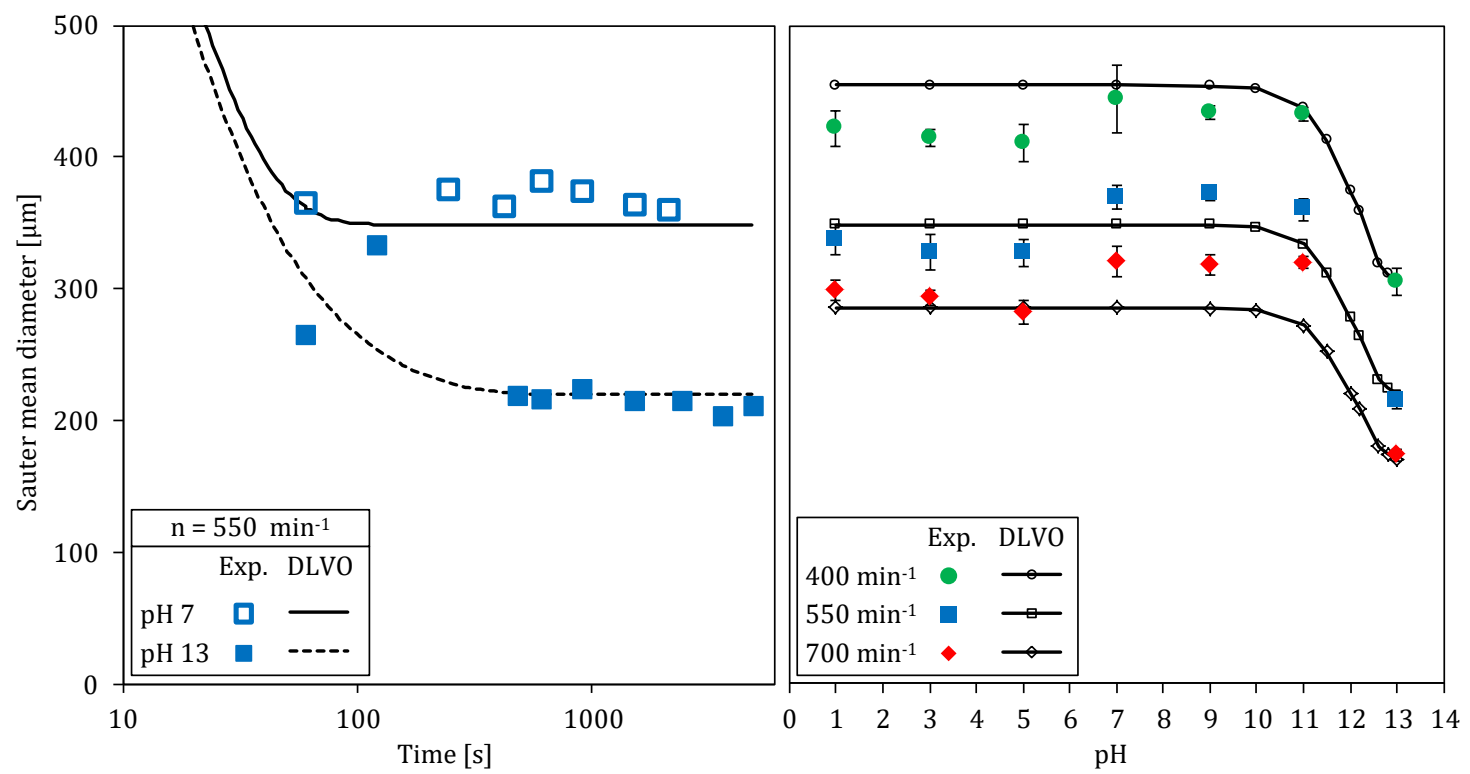

Figure 5: Simulations using the Coulaloglou and Tavlarides (1977) model extended with the DLV0 model $(D L V O)$ in comparison with experimental data. Left: transient Sauter mean diameter $d_{32}$ at $n=550$ min $^{-1}$, right: stationary $d_{32, \text { stat }}$ vs. pH of continuous phase.

Table 4: Root-mean-square deviations of stationary Sauter mean diameters from simulations using Coulaloglou and Tavlarides (1977) model extended with the DLVO model vs. $\mathrm{pH}$.

\begin{tabular}{lllll}
\hline stirrer frequency $\boldsymbol{n}$ & $\mathbf{4 0 0} \mathbf{~ m i n}^{-\mathbf{1}}$ & $\mathbf{5 5 0} \mathbf{~ m i n}^{-\mathbf{1}}$ & $\mathbf{7 0 0} \mathbf{~ m i n}^{-\mathbf{1}}$ & total \\
\hline $\operatorname{RMSD}\left(d_{d 32, s t a t}\right) \operatorname{DLVO}$ & $26.90 \mu \mathrm{m}$ & $19.93 \mu \mathrm{m}$ & $26.56 \mu \mathrm{m}$ & $24.67 \mu \mathrm{m}$ \\
\hline
\end{tabular}

\subsubsection{Transient behaviour}

In the investigations shown above (Figure 2, Figure 3 and Figure 5) the transient development of the Sauter mean diameter $d_{32}$ occurs in the short time span $<100 \mathrm{~s}$ after starting the impeller, where drop breakage is dominant. Due to the experimental cycle which takes around $30-60 \mathrm{~s}$ for preparation and image acquisition more data points could not be achieved in this time span. Thus, 
the standard procedure to investigate the transient behaviour of a system is to change the stirrer frequency stepwise in an experiment. Particularly the coalescence behaviour can be examined if the stirrer speed is decreased abruptly after a steady state has been reached. This was investigated in experiments by changing the stirrer frequency from $n=700 \mathrm{~min}^{-1}$ to $400 \mathrm{~min}^{-1}$ and simulated with the given numerical parameters (see Table 2) to analyse the transient behaviour of the three coalescence efficiency sub models. In Figure 6 the results are shown for pH 13, where coalescence is inhibited and the transient development of the drop size is well observable.

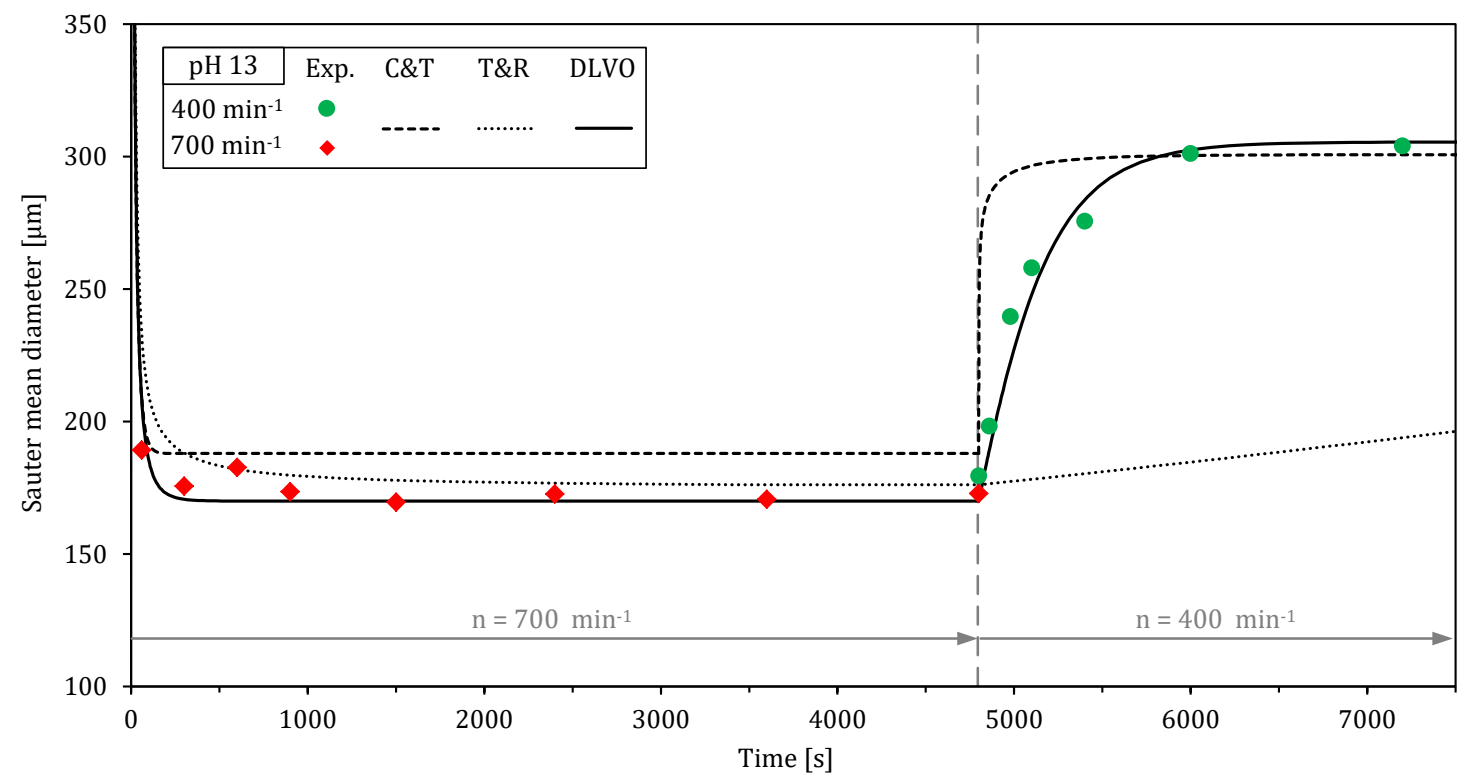

Figure 6: Transient development of the Sauter mean diameter $d_{32}$ at pH 13 with a change in stirrer frequency $n$ from $700 \mathrm{~min}^{-1}$ to $400 \mathrm{~min}^{-1}$ after $80 \mathrm{~min}$ in experiments and simulations using the three coalescence efficiency sub models (C\&T: Coulaloglou and Tavlarides (1977), T\&R: Tobin and Ramkrishna (1999), DLVO: hydrodynamic model from Coulaloglou and Tavlarides (1977) extended with DLVO model).

In the first part of this experiment with a stirrer frequency of $n=700 \mathrm{~min}^{-1}$ no significant transient behaviour can be observed experimentally because drop breakage occurs fast in this system and obviously is the dominant phenomenon after starting the impeller. The steady state is reached after a few minutes. This is described adequately by all three sub models as discussed above, whereas the Coulaloglou and Tavlarides (1977) model differs in the steady state and the transient behaviour of the Tobin and Ramkrishna (1999) model is too slow. After 80 minutes when the stirrer frequency was changed to $n=400 \mathrm{~min}^{-1}$ coalescence predominates breakage and the Sauter mean diameter $d_{32}$ increases during the following 10 minutes until a steady state is reached again. The stationary Sauter mean diameter $d_{32, \text { stat }}$ is equal to the one achieved starting with $\mathrm{n}=400 \mathrm{~min}^{-1}$ (compare to Figure 2, Figure 3 and Figure 5 right hand side at $\mathrm{pH}$ 13). The only coalescence efficiency model describing this transient behaviour well is the Coulaloglou and Tavlarides (1977) model extended with the DLVO model. The sole Coulaloglou and Tavlarides (1977) model overestimates the coalescence rate and therefore predicts a too fast transient development of the Sauter mean diameter. In contrast, the Tobin and Ramkrishna (1999) model underestimates the coalescence rate and the increase of $d_{32}$ cannot be described properly.

\subsubsection{Drop size distributions}

The Sauter mean diameter $d_{32}$ is an important quantity to evaluate the drop size distribution in technical applications with one numerical value, nevertheless the underlying drop size distribution 
itself should also be described by the applied models. In Figure 7 the cumulative particle volume distributions from experiments (corresponding to the last measurement point of the transient graphs) and simulations with all discussed coalescence efficiency models are shown in a normal probability plot at $\mathrm{pH} 7$ and $\mathrm{pH} 13$. In the experiments no significant difference in the drop size distributions could be observed for $\mathrm{pH} 1$ - 11, thus the distributions at pH 7 are shown exemplarily for all acidic and moderate alkaline conditions.

As coalescence is obviously hindered at $\mathrm{pH} 13$ due to electrostatic repulsion, the growth of bigger droplets is inhibited in comparison to $\mathrm{pH} \leq 11$ which causes smaller droplets in general. Simultaneously, the breakage probability is not affected by the change of pH (Kamp et al., 2012), thus the rate of drop breakage is constant. This affects mainly bigger droplets, because breakage is more probable for these in general (Liao and Lucas, 2009). These two effects lead to a narrower drop size distribution, which was found experimentally at $\mathrm{pH} 13$. Additionally, the interfacial tension decreases slightly from 35 to $32 \mathrm{mN} / \mathrm{m}$. This reduces the minimal stable droplet size which can be observed by the slight decrease of the minimal drop size in the distributions.

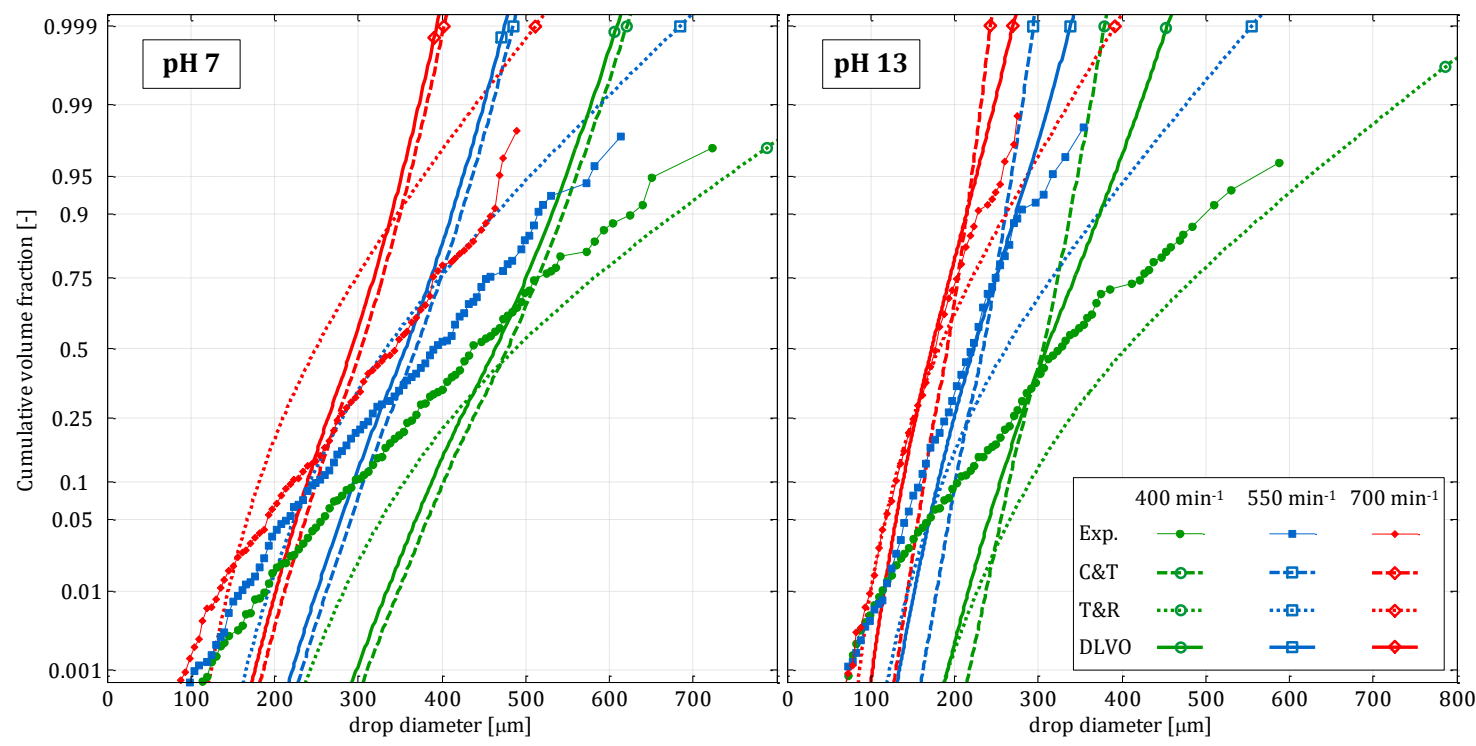

Figure 7: Cumulative particle volume distributions from experiments (Exp.) and all simulations with different coalescence efficiency models (C\&T: Coulaloglou and Tavlarides (1977), T\&R: Tobin and Ramkrishna (1999), DLVO: hydrodynamic model from Coulaloglou and Tavlarides (1977) extended with DLVO model) performed at pH 7 (left) and pH 13 (right).

The experimental particle volume distributions are mainly distributed normally as they are displayed linearly in the normal probability plot. Although the simulations fit well concerning the Sauter mean diameter, the simulations at $\mathrm{pH} 7$ do not describe the experimental distributions well. However, it has to be considered that this representation emphasizes the tails of the distribution and the definition of the Sauter mean diameter is predominantly determined by the large particles in the distribution. Additionally, the experimental $d_{32}$ differ from the predicted ones at the distinct $\mathrm{pH}$ value of 7 (see Figure 2, Figure 3 and Figure 5). Nevertheless, the width of the distributions (corresponding to the slope of the graphs) between simulations and experiments do not match. The experimental distributions at $\mathrm{pH} 13$ with stirrer frequencies of $n=550 \mathrm{~min}^{-1}$ and $700 \mathrm{~min}^{-1}$ are significantly narrower than at $\mathrm{pH}$ 7. These distributions are described well by the simulations using the Coulaloglou and Tavlarides (1977) coalescence efficiency. The accordance with the experiments becomes better extending the simulation with the DLVO model. At $n=400 \mathrm{~min}^{-1}$ the experimental distribution is similar to the one at $\mathrm{pH}$ 7. This difference is not depicted by any model applied. 
Throughout most system conditions the model of Tobin and Ramkrishna (1999) shows the largest deviations from the experimental distributions.

The narrow distributions in the simulations are mainly determined by the daughter drop size distribution of the breakage kernel. Due to mass balance conservation a relatively narrow normal distribution was applied (see section 2.3). A broader daughter drop size distribution would lead to broader distributions in the simulations but also result in a significant loss of mass during simulation. Using an advanced daughter drop size distribution based on single drop breakage investigations, Maaß et al. (2007) showed that the broad experimental distributions can be predicted well. As the focus in this work lies on the coalescence modelling, the breakage kernel was kept as basic as possible and confined to the Coulaloglou and Tavlarides (1977) model.

\section{Summary and outlook}

The presented implementation of the DLVO theory into population balance equations offers the possibility to extend hydrodynamic models of coalescence efficiency so that the coalescence inhibition due to electrostatic effects can be described effectively. This was applied for drop size distribution measurements in a stirred tank with $\mathrm{NaOH}, \mathrm{NaCl}$ and $\mathrm{HCl}$ present and an ionic strength of $I=0.1 \mathrm{~mol} / \mathrm{L}$. The coalescence inhibition at high $\mathrm{pH}$ values was modelled successfully extending the model of Coulaloglou and Tavlarides (1977) with the developed DLVO model using only constant numerical parameters. The gained results are able to describe the steady state and transient experimental data better than the models of Coulaloglou and Tavlarides (1977) or Tobin and Ramkrishna (1999), where a parameter variation is inevitable to describe the $\mathrm{pH}$ dependency of the Sauter mean diameter.

The surface potential has to be known, but may be approximated with the zeta potential. As the type of oil has a minor influence on the $\mathrm{pH}$ dependency of the zeta potential, the presented model can be adapted to several investigations available in literature (e.g. Creux et al. (2009), Gray-Weale and Beattie (2009) and Marinova et al. (1996)) for different salts and conditions. If proper data is not available, the zeta potential can be measured and its $\mathrm{pH}$ dependency can be described with Stern adsorption isotherm and Grahame equation as presented in this work.

In integral applications of the population balance equation trajectories of single droplets and therefore distances between drops are not available. Hence, the Debye length is defined as the characteristic distance between the drops to calculate the attractive van der Waals and the repulsive electrostatic force.

An interesting further improvement of this DLVO model could be a general description of the $\mathrm{pH}$ dependency of the zeta potential for varying ionic strength and the implementation of other ionic species. Additionally, the model equations could be extended to describe also the presence of multivalent ions.

\section{Acknowledgements}

The authors kindly thank Mirco Wegener for providing the experimental data and the student workers Elies Espí Novell and Jin Zoo Lee who substantially contributed to this work. Moreover, the authors kindly thank the Institute of Soft Matter and Functional Materials at Helmholtz Zentrum Berlin for providing the possibility of measuring the zeta potential. Financial support provided by the German Research Foundation (DFG) within the project KR 1639/19-1 is gratefully acknowledged. 


\section{Nomenclature}

Latin letters$$
[\mathrm{m}]
$$$$
\text { a numerical parameter in isotherm fit }
$$

$A_{1,2,3}$

Hamaker constant

$n_{d} \quad$ number of daughter drops after breakage event: 2

$\mathrm{pH}$ decimal logarithm of the reciprocal hydrogen ion activity 


$\begin{array}{lll}V_{p} & \text { particle / droplet volume } & {\left[\mathrm{m}^{3}\right]} \\ V_{\mu} & \text { mean value of daughter drop volume distribution } & {\left[\mathrm{m}^{3}\right]} \\ V_{\sigma} & \text { standard deviation of daughter drop volume distribution } & {\left[\mathrm{m}^{3}\right]} \\ X_{i} & \text { experimental value } & \text { various } \\ \hat{X}_{i} & \text { calculated value } & \text { various } \\ z_{i} & \text { valence / charge number of ion } i & {[-]} \\ \text { Greek letters } & \\ \beta & \text { daughter drop size distribution } & {[-]} \\ \epsilon & \text { energy dissipation rate } & {\left[\mathrm{m}^{2} / \mathrm{s}^{3}\right]} \\ \varepsilon_{r} & \text { relative permittivity } & {[-]} \\ \varepsilon_{0} & \text { vacuum permittivity: } 8.8542 \cdot 10^{-12} \mathrm{~F} / \mathrm{m} & {[\mathrm{F} / \mathrm{m}]} \\ \gamma & \text { interfacial tension } & {[\mathrm{N} / \mathrm{m}]} \\ \kappa & \text { inverse Debye length } & {\left[\mathrm{m}^{-1}\right]} \\ \lambda & \text { coalescence efficiency / probability } & {[-]} \\ \Gamma_{i} & \text { number concentration of ion } i \text { at surface / interface } & {\left[\mathrm{m}^{-2}\right]} \\ \Gamma_{0} & \text { reference saturation adsorption at surface / interface } & {\left[\mathrm{m}^{-2}\right]} \\ v_{i} & \text { volume of hydrated ion } i & {\left[\mathrm{~m}^{3}\right]} \\ \varphi & \text { phase fraction } & {[-]} \\ \Phi_{i} & \text { specific interaction energy of ion } i & {[\mathrm{~J}]} \\ \Psi_{s} & \text { surface potential } & {[\mathrm{V}]} \\ \sigma & \text { surface charge density } & {\left[\mathrm{C} / \mathrm{m}^{2}\right]} \\ \theta_{i} & \text { surface coverage of ion } i & {[-]} \\ \xi & \text { collision frequency } & {\left[\mathrm{m}^{3} / \mathrm{s}\right]} \\ \zeta & \text { zeta potential } & {[\mathrm{V}]} \\ & & \end{array}$

\section{Abbreviations}

$\begin{array}{ll}\text { C\&T } & \text { Coulaloglou and Tavlarides (1977) } \\ \text { DLVO } & \text { Derjaguin, Landau, Verwey \& Overbeek theory } \\ \text { PBE } & \text { Population balance equation(s) } \\ \text { PTFE } & \text { Polytetrafluoroethylene } \\ \text { RMSD } & \text { root-mean-square deviation } \\ \text { T\&R } & \text { Tobin and Ramkrishna (1999) }\end{array}$

\section{Literature}

Attarakih, M.M., Bart, H.-J., Faqir, N.M., 2004. Numerical solution of the spatially distributed population balance equation describing the hydrodynamics of interacting liquid-liquid dispersions. Chem. Eng. Sci. 59, 2567-2592. http://dx.doi.org/10.1016/j.ces.2004.03.005

Beattie, J.K., Djerdjev, A.M., 2004. The Pristine Oil/Water Interface: Surfactant-Free HydroxideCharged Emulsions. Angew. Chemie 116, 3652-3655. http://dx.doi.org/10.1002/ange.200453916

Beattie, J.K., Djerdjev, A.M., Franks, G. V, Warr, G.G., 2005. Dipolar Anions Are Not Preferentially Attracted to the Oil/Water Interface. J. Phys. Chem. B 109, 15675-15676.

http://dx.doi.org/10.1021/jp052894l 
Beattie, J.K., Gray-Weale, A., 2012. Oil/Water Interface Charged by Hydroxide Ions and Deprotonated Fatty Acids: A Comment. Angew. Chemie Int. Ed. 51, 12941-12942. http://dx.doi.org/10.1002/anie.201205927

Butt, H.-J., Graf, K., Kappl, M., 2003. Physics and Chemistry of Interfaces (Physics Textbook). WileyVCH, Weinheim. http://dx.doi.org/10.1002/3527602313

Carroll, B.J., 1976. The stability of emulsions and mechnisms of emulsion breakdown, in: Matijevic, E. (Ed.), Surface and Colloid Science. Wiley-Interscience, New York, pp. 1-68.

Chibowski, E., Wiacek, A.E., Holysz, L., Terpilowski, K., 2005. Investigation of the electrokinetic properties of paraffin suspension. 1. In inorganic electrolyte solutions. Langmuir 21, 43474355. http://dx.doi.org/10.1021/la046921v

Coulaloglou, C.A., Tavlarides, L.L., 1977. Description of interaction processes in agitated liquidliquid dispersions. Chem. Eng. Sci. 32, 1289-1297. http://dx.doi.org/10.1016/00092509(77)85023-9

Creux, P., Lachaise, J., Graciaa, A., Beattie, J.K., Djerdjev, A.M., 2009. Strong Specific Hydroxide Ion Binding at the Pristine Oil/Water and Air/Water Interfaces. J. Phys. Chem. B 113, 1414614150. http://dx.doi.org/10.1021/jp906978v

David, F., Vokhminz, V., Ionova, G., 2001. Water Characteristics Depend on the Ionic Environment. Thermodynamics and Modelisation of the Aquo Ions. J. Mol. Liq. 90, 45-62. http://dx.doi.org/10.1016/S0167-7322(01)00106-4

Delgado, A. V, González-Caballero, F., Hunter, R.J., Koopal, L.K., 2007. Measurement and interpretation of electrokinetic phenomena. J. Colloid Interface Sci. 309, 194-224. http://dx.doi.org/10.1016/j.jcis.2006.12.075

Derjaguin, B., 1934. Untersuchungen über die Reibung und Adhäsion, IV. Kolloid-Zeitschrift 69, 155-164. (in German). http://dx.doi.org/10.1007/bf01433225

Derjaguin, B. V, 1989. Theory of Stability of Colloids and Thin Films. Consultants Bureau, New York.

Derjaguin, B. V, Churaev, N. V, Muller, V.M., 1987. Surface Forces. Consultants Bureau, New York.

Derjaguin, B. V, Landau, E.M., 1941. Theory of the stability of strongly charged lyophobic sols and of the adhesion of strongly charged particles in solutions of electrolytes. Acta Physicochitnica U.R.S.S. 14, 633-662. (reprint: Progress in Surface Science, 1993 (43), 30-59, http://dx.doi.org/10.1016/0079-6816(93)90013-L). http://dx.doi.org/10.1016/00796816(93)90013-L

Dunstan, D.E., 1992. The Electrophoretic Mobility of Hydrocarbon Particles in KCl Solutions. Langmuir 8, 1507-1508. http://dx.doi.org/10.1021/la00042a002

Franks, G. V, Djerdjev, A.M., Beattie, J.K., 2005. Absence of Specific Cation or Anion Effects at Low Salt Concentrations on the Charge at the Oil/Water Interface. Langmuir 21, 8670-8674. http://dx.doi.org/10.1021/la051379b

Gäbler, A., 2007. Experimentelle Untersuchungen, Modellierung und Simulation gerührter Flüssig/flüssig-Systeme mit veränderlichen Stoff- und Betriebsparametern. PhD Thesis, Technische Universität Berlin, Fachgebiet Verfahrenstechnik. (in German)

Gäbler, A., Wegener, M., Paschedag, A.R., Kraume, M., 2006. The effect of pH on experimental and simulation results of transient drop size distributions in stirred liquid-liquid dispersions. Chem. Eng. Sci. 61, 3018-3024. http://dx.doi.org/10.1016/j.ces.2005.10.072

Gray-Weale, A., Beattie, J.K., 2009. An explanation for the charge on water's surface. Phys. Chem. Chem. Phys. 11, 10994. http://dx.doi.org/10.1039/b901806a

Hamaker, H.C., 1937. The London-Van der Vaals attraction between spherical particles. Phys. IV 10, 1058-1072. http://dx.doi.org/10.1016/S0031-8914(37)80203-7

Hulburt, H.M., Katz, S., 1964. Some problems in particle technology. Chem. Eng. Sci. 19, 555-574. http://dx.doi.org/10.1016/0009-2509(64)85047-8

Israelachvili, J.N., 1991. Intermolecular and Surface Forces, 2nd ed. Academic Press, London.

Izutsu, K., 2002. Electrochemistry in Nonaqueous Solutions. Wiley-VCH, Weinheim. 
Jou, F.-Y., Mather, A.E., 2003. Liquid-Liquid Equilibria for Binary Mixtures of Water + Benzene, Water + Toluene, and Water + p -Xylene from $273 \mathrm{~K}$ to $458 \mathrm{~K}$. J. Chem. Eng. Data 48, 750-752. http://dx.doi.org/10.1021/je034033g

Kamp, J., Nachtigall, S., Maaß, S., Kraume, M., 2012. Modelling of coalescence in turbulent liquid/liquid dispersions considering droplet charge. Czas. Tech. Mech. Politech. Krak. 109, 113-124. (Errata in: http://www.verfahrenstechnik.tuberlin.de/fileadmin/fg158/Dokumente/Manuskripte/2012/Kamp_CTM_2012_Manuskript.pdf)

Kopriwa, N., Buchbender, F., Ayesteran, J., Kalem, M., Pfennig, A., 2012. A Critical Review of the Application of Drop-Population Balances for the Design of Solvent Extraction Columns: I. Concept of Solving Drop-Population Balances and Modelling Breakage and Coalescence. Solvent Extr. Ion Exch. 30, 683-723. http://dx.doi.org/10.1080/07366299.2012.700598

Kraume, M., Gäbler, A., Schulze, K., 2004. Influence of physical properties on drop size distributions of stirred liquid-liquid dispersions. Chem. Eng. Technol. 27, 330-334. http://dx.doi.org/10.1002/ceat.200402006

Liao, Y., Lucas, D., 2009. A literature review of theoretical models for drop and bubble breakup in turbulent dispersions. Chem. Eng. Sci. 64, 3389-3406. http://dx.doi.org/10.1016/j.ces.2009.04.026

Liao, Y., Lucas, D., 2010. A literature review on mechanisms and models for the coalescence process of fluid particles. Chem. Eng. Sci. 65, 2851-2864. http://dx.doi.org/10.1016/j.ces.2010.02.020

Lyklema, J., 2000. Fundamentals of Interface and Colloid Science Vol. III: Liquid-fluid interfaces, Fundamentals of Interface and Colloid Science. Academic Press, London.

Maaß, S., Gäbler, A., Zaccone, A., Paschedag, A.R., Kraume, M., 2007. Experimental Investigations and Modelling of Breakage Phenomena in Stirred Liquid/Liquid Systems. Chem. Eng. Res. Des. 85, 703-709. http://dx.doi.org/10.1205/cherd06187

Maaß, S., Wollny, S., Voigt, A., Kraume, M., 2011. Experimental comparison of measurement techniques for drop size distributions in liquid/liquid dispersions. Exp. Fluids 50, 259-269. http://dx.doi.org/10.1007/s00348-010-0918-9

Marinova, K.G., Alargova, R.G., Denkov, N.D., Velev, O.D., Petsev, D.N., Ivanov, I.B., Borwankar, R.P., 1996. Charging of Oil-Water Interfaces Due to Spontaneous Adsorption of Hydroxyl Ions. Langmuir 12, 2045-2051. http://dx.doi.org/10.1021/la950928i

Miller, C.A., Neogi, P., 2008. Interfacial phenomena: equilibrium and dynamic effects, Surfactant science series. CRC Press, Taylor \& Francis, Boca Raton, FL.

Overbeek, J.T.G., 1952. Electrochemistry of the double layer, in: Kruyt, H.R. (Ed.), Colloid Science: Irreversible Systems. Elsevier, Amsterdam, pp. 115-193.

Pfennig, A., Schwerin, A., 1998. Influence of Electrolytes on Liquid-Liquid Extraction. Ind. Eng. Chem. Res. 37, 3180-3188. http://dx.doi.org/10.1021/ie970866m

Rambhau, D., 1978. Zeta potential: a force that monitors dispersion stability. Indian J. Pharm. Educ. $12,140-151$.

Rambhau, D., Phadke, D.S., Dorle, A.K., 1977. Evaluation of o/w emulsion stability through zeta potential. I. J. Soc. Cosmet. Chem. 28, 183-196.

Ramkrishna, D., 1985. Status of population balances. Rev. Chem. Eng. 3, 49-95. http://dx.doi.org/10.1515/REVCE.1985.3.1.49

Ramkrishna, D., 2000. Population Balances: Theory and Applications to Particulate Systems in Engineering. Academic Press, San Diego.

Randolph, A.D., Larson, M.A., 1962. Transient and steady state size distributions in continuous mixed suspension crystallizers. AIChE J. 8, 639-645. http://dx.doi.org/10.1002/aic.690080515

Ritter, J., Kraume, M., 2000. On-line Measurement Technique for Drop Size Distributions in Liquid/Liquid Systems at High Dispersed Phase Fractions. Chem. Eng. Technol. 23, 579-581. http://dx.doi.org/10.1002/1521-4125(200007)23:7<579::AID-CEAT579>3.0.C0;2-Y

Roger, K., Cabane, B., 2012a. Why Are Hydrophobic/Water Interfaces Negatively Charged? Angew. Chemie Int. Ed. 51, 5625-5628. http://dx.doi.org/10.1002/anie.201108228 
Roger, K., Cabane, B., 2012b. Uncontaminated Hydrophobic/Water Interfaces Are Uncharged: A Reply. Angew. Chemie 124, 13117-13119. http://dx.doi.org/10.1002/ange.201207114

Rosenholm, J.B., 2010. Critical comparison of molecular mixing and interaction models for liquids, solutions and mixtures. Adv. Colloid Interface Sci. 156, 14-34. http://dx.doi.org/10.1016/j.cis.2010.02.005

Smoluchowski, M., 1903. Contribution à la théorie l'endosmose électrique et de quelques phénomènes corrélatifs. Bull. Int. l'Académie des Sci. Cracovie, Cl. des Sci. Mathématiques Nat. 182-199. (in French)

Stern, 0., 1924. Zur Theorie der elektrolytischen Doppelschicht. Z. Elektrochem. Angew. Phys. Chem. 30, 508-516. (in German). http://dx.doi.org/10.1002/bbpc.192400182

Tian, C.S., Shen, Y.R., 2009. Structure and charging of hydrophobic material/water interfaces studied by phase-sensitive sum-frequency vibrational spectroscopy. Proc. Natl. Acad. Sci. 106, 15148-15153. http://dx.doi.org/10.1073/pnas.0901480106

Tobin, T., Ramkrishna, D., 1992. Coalescence of charged droplets in agitated liquid-liquid dispersions. AIChE J. 38, 1199-1205. http://dx.doi.org/10.1002/aic.690380807

Tobin, T., Ramkrishna, D., 1999. Modeling the effect of drop charge on coalescence in turbulent liquid-liquid dispersions. Can. J. Chem. Eng. 77, 1090-1104. http://dx.doi.org/10.1002/cjce.5450770603

Tsonopoulos, C., 2001. Thermodynamic analysis of the mutual solubilities of hydrocarbons and water. Fluid Phase Equilib. 186, 185-206. http://dx.doi.org/10.1016/S0378-3812(01)005209

Vacha, R., Rick, S.W., Jungwirth, P., de Beer, A.G.F., de Aguiar, H.B., Samson, J.-S., Roke, S., 2011. The Orientation and Charge of Water at the Hydrophobic Oil Droplet-Water Interface. J. Am. Chem Soc. 133, 10204-10210. http://dx.doi.org/10.1021/ja202081x

Verwey, E.J.W., Overbeek, J.T.G., 1948. Theory of the Stability of Lyophobic Colloids. Elsevier, New York.

Villwock, J., Gebauer, F., Kamp, J., Bart, H.-J., Kraume, M., 2014. Systematic Analysis of Single Droplet Coalescence. Chem. Eng. Technol. 37, 1103-1111. http://dx.doi.org/10.1002/ceat.201400180

Wagner, K., Friese, T., Schulz, S., Ulbig, P., 1998. Solubilities of Sodium Chloride in Organic and Aqueous-Organic Solvent Mixtures. J. Chem. Eng. Data 43, 871-875. http://dx.doi.org/10.1021/je9800510

Wang, T., Wang, J., Jin, Y., 2003. A novel theoretical breakup kernel function for bubbles/droplets in a turbulent flow. Chem. Eng. Sci. 58, 4629-4637. http://dx.doi.org/10.1016/j.ces.2003.07.009

Watanabe, A., 1984. Electrochemistry of oil-water interfaces, in: Matijevic, E. (Ed.), Surface and Colloid Science. Wiley-Interscience, New York, pp. 1-70.

Wegener, M., 2004. Experimentelle Untersuchungen und Modellierung von transienten Tropfengrößenverteilungen in gerührten Flüssig-flüssig-Systemen. Master Thesis, Chair of Chemical and Process Engineering, Technische Universität Berlin. (in German)

Wulkow, M., Gerstlauer, A., Nieken, U., 2001. Modeling and simulation of crystallization processes using parsival. Chem. Eng. Sci. 56, 2575-2588. http://dx.doi.org/10.1016/S00092509(00)00432-2

Zaccone, A., Gäbler, A., Maaß, S., Marchisio, D., Kraume, M., 2007. Drop breakage in liquid/liquid stirred dispersions: Modelling of single drop breakage. Chem. Eng. Sci. 62, 6297-6307. http://dx.doi.org/10.1016/j.ces.2007.07.026 